\title{
Agricultural Product Types and Household Income Contribution in Mhondoro-Mubaira (Zimbabwe)
}

\author{
Evans Muchesa, Douglas Nkosi, Elliot Zwane, Johan Van Niekerk \\ Centre for Sustainable Agriculture, Rural Development, and Extension, Bloemfontein, South Africa \\ Email address: \\ e.muchesa@gmail.com (E. Muchesa),dnkosi@arc.agric.za(D. Nkosi), elliot.zwane@ul.ac.za (E. Zwane), \\ vNiekerkJA@ufs.ac.za (J. V. Niekerk)
}

\section{To cite this article:}

Evans Muchesa, Douglas Nkosi, Elliot Zwane, Johan Van Niekerk. Agricultural Product Types and Household Income Contribution in Mhondoro-Mubaira (Zimbabwe). International Journal of Agricultural Economics. Vol. 3, No. 4, 2018, pp. 83-88.

doi: $10.11648 /$ j.ijae.20180304.14

Received: August 14, 2018; Accepted: September 1, 2018; Published: September 21, 2018

\begin{abstract}
The objective of this research was to examine agricultural product types and their contribution to the household income for communal farmers in Mhondoro-Mubaira area. The study was carried out in the area of Mhondoro-Mubaira, situated in Mashonaland West province of Zimbabwe. The target population samples for the study comprised of communal farmers $(\mathrm{N}=150)$ and the extension officers $(\mathrm{N}=25)$. According to the results, remittances and gifts $(92.66 \%)$ are the major contributors of household income for most communal farmers. This is because of the current bad economic situation and frequent droughts. Despite remittances and gifts being the major household income, farmers still perceive farming has very important contributor to their daily sustenance. The study proves that field crops and maize in particular is a strategic crop in Zimbabwe. Maize is not only for household consumption but also for selling. Tobacco is the most important cash crop for the farmers because of good prices and well-established markets. Farmers indicated that open markets are important but because of unscrupulous traders and lack of monitoring and poor regulations, farmers are prone to being cheated and price manipulations. The government and private sector can contribute in formalizing and improving growing of garden crops. The government should improve and invest in non-farm economy which contributes to communal farmer standard of leaving such has roads, electricity, and related infrastructure. This will inherently improve the farm economy and the livelihood status of the communal farmers.
\end{abstract}

Keywords: Mashonaland West, Maize, Tobacco, Marketing, Income Contribution, Non-farm Economy, Communal Farmer

\section{Introduction}

The objective of this research was to examine agricultural product types and their contribution to the household income for communal farmers in Zimbabwe. The study examined the major agricultural products, which are produced by the farmers, and then document their level of contribution to the household income. A considerable number of researches such as; [1-5] show that economic contribution of agricultural activities for most low-income households is about 12.0 percent of the total household income. The importance of growing the percentage of agricultural activities contribution is critical in addressing food insecurity and poverty. The productivity of crop production is generally related to the intensive use of inputs, but smallholder farmers can also increase their yields through better land management and farming practices. A number of poor practices include poor market information and market extension has been identified [6]. Categorisation of non-farm and farm income options is critical in establishing the most important household income streams for the communal farmers. The rural non-farm and farm economies framework was used in establishing the level of importance of agricultural enterprises to communal livelihoods in Zimbabwe.

\section{Hypothesis}

$\mathrm{H}_{0}=$ different agricultural product types contribute differently to communal household income. 


\section{Conceptual Framework}

The rural non-farm and farm economies framework. The rural economy comprises of a range of livelihoods aspects and is not only limited to the agricultural sector and production of primary produce [7]. The rural economy is categorized into the agricultural/farm sector producing primary goods; and the non-agriculture/non-farm sector, which includes all non-agricultural economic activities that may indirectly/directly and contribute to household income or at a community level development. These may include but not limited to; mining, manufacturing, utilities, construction, commerce, tourism, transport, and financial, personal and government services [8].

The economic diversification of the rural economy means the transition between agriculture to non-farm sector activities within rural areas, or to the diversification of economic outputs thereof (see Figure 1). He asserts that a developed non-farm economy [8] has direct benefits to the farm economy through diversification.

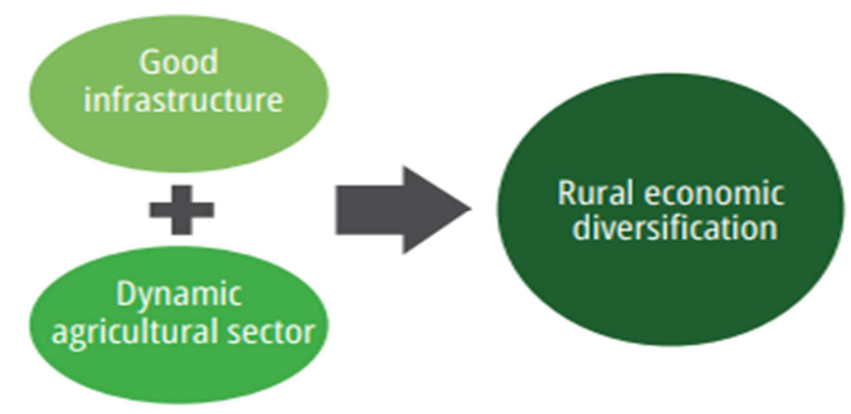

Figure 1. Economic Diversification of the rural economy (Barrett et al., 2001).

The rural non-farm and farm economies framework is critical in reducing poverty, rural economic diversification, both within agriculture and into non-agricultural activities, increase coping mechanisms in face of crop failure or price volatility, and improve food and livelihood security of rural households [9]. There is considerable evidence that rural non-farm economy is critical for agricultural growth. Nonfarm economy plays a supporting function and is responsible for activities like road construction and maintenance, schools, health, money transfer facilities like Mukuru-for remittances, food processors just to name a few [9]. So, for the stimulation of agricultural production in the rural areas, there is a need of development and support of the non-farm economy in the communal areas from the government and private role players.

\section{Methods}

The target population for the research were communal farmers ${ }^{1}$ and public extension officers located in the
Mhondoro-Mubaira which is a constituency in the Chegutu district. The descriptive research interviewed a total of 150 communal farmers and cluster sampling was used. A total of 25 frontline extension personnel was interviewed using convenience sampling. Extension officers were selected on the basis that they work in the Ministry of Agriculture, and they serve under Mhondoro-Mubaira area. The primary data on extension support and agricultural marketing was collected on Section A, B of the Appendix A (Farmers questionnaire) and Section A, B of the Appendix B (extension questionnaire) both structured questionnaires. Semi-structured interviews were done at randomly selected farmer in the Mhondoro-Mubaira communal area. The structure of the questionnaire is composed of Likert scale questions, open ended questions and multiple-choice questions. The data collected from the farmers was captured and coded in MS Excel spreadsheet and cleaned by checking for capturing errors. The Statistical Analysis System (SAS) Statistical 9.4 (2016) package was used to analyze the quantitative data. Chi-square test was used to establish the associations within data. The researcher obtained the required permission from the respondents after informing them about the purpose of the interview and the investigation. Then the respondents were assured that information provided would remain confidential. And the researcher confirmed that participation was voluntary and respondents have the right to withdraw at any time. Furthermore, the respondents were also given the right to ask questions, and obtain further clarity to the questions.

\section{Results}

\subsection{Communal Farmers Profile}

According to the results women are the largest communal landholders $(68.0 \% ; \mathrm{p}=0.0001)$. The typical land holding per communal household is between 4 to 5 ha $(66.0 \% ; \mathrm{p}=0001)$, and this includes the homestead. $18.7 \%$ of the farmers are above the 60 years, and $40.0 \%$ are in the 51- 60 years age group. A total $68.7 \%$ of the communal farmers are above the age of 50. This is a common age distribution among the communal areas in Zimbabwe. This is because most individuals when they retire

from when relocate permanently to the communal areas. Female farmers make up more than $60 \%$ of total farmers in communal areas in Mhondoro-Mubaira area, migration to town or other countries for males is still a dominate phenomenon [10]. The educational level for the communal farmers in Mhondoro-Mubaira communal area, the results show that $73.0 \% \quad(p=0.0001)$ of the farmers have only secondary level education and below. Consideration of educational level for the farmers is important for agricultural extension delivery methods [7].

areas are generally poorly resourced and poorly supported (Claasens, 2008)
Communal farmers are farmers farming in areas designated has communal farming area according to the communal land act [Chapter 20:04]. Communal farmers constitute almost $50 \%$ of the farmer category in Zimbabwe. Communal 


\subsection{Agricultural Product Types and Household Income Contribution}

Table 1, below shows the major sources of household income and the level of importance. Most farmers rated (with ratings $3>$ ) remittances from relatives and gifts $(92.66 \%)$ as a major income for the household, there is substantial contribution with statistical significance of $p=0.0043$. The current economic condition in Zimbabwe has seen many people migrate to major towns, or immigrate to neighboring countries such as South Africa and Botswana. Remittances have become major source of incomes for most rural households, this is because of the; collapse of the Zimbabwean economy [7] Despite many farmers rating remittances from relatives and gift and a major source of household income, farming is still the important mainstay of the communal households. All the farmers (100\%) indicated that farming is an important contributor to the household income. Farming remains the most important contributor because of the land use planning inherently embedded in the designs of the communal lands in Zimbabwe [8]

Table 1. Major sources of household income and level of importance $(N=150)$.

\begin{tabular}{|c|c|c|c|c|c|c|c|c|c|c|c|c|c|}
\hline \multirow{3}{*}{ Source of income } & \multicolumn{10}{|c|}{ Ratings } & \multirow{2}{*}{\multicolumn{3}{|c|}{ Chi-Square Test }} \\
\hline & \multicolumn{2}{|l|}{1} & \multicolumn{2}{|l|}{2} & \multicolumn{2}{|l|}{3} & \multicolumn{2}{|l|}{4} & \multicolumn{2}{|l|}{5} & & & \\
\hline & $\mathbf{F}$ & $\%$ & $\mathbf{F}$ & $\%$ & $\mathbf{F}$ & $\%$ & $\mathbf{F}$ & $\%$ & $\mathbf{F}$ & $\%$ & $X^{2}$ & df & $\mathbf{p}$ \\
\hline Farming & 0 & 0 & 0 & 0 & 33 & 22 & 51 & 34 & 66 & 44 & 10.9200, & 2 & $<.0043$ \\
\hline Wages from employment & 6 & 18 & 14 & 41.18 & 11 & 32.4 & 0 & 0 & 3 & 8.82 & 8.5882 & 3 & $<.0353$ \\
\hline Pension & 0 & 0 & 2 & 100 & 0 & 0 & 0 & 0 & 0 & 0 & 0.0000 & 0 & 0 \\
\hline Agriculture Trading & 4 & 3.0 & 21 & 15.67 & 83 & 61.9 & 2 & 1.49 & 24 & 17.9 & 161.7463, & 4 & $<.0001$ \\
\hline
\end{tabular}

Table 2, shows the farming enterprises carried out by the farmers and ratings on their importance to household income. The farmers indicated all the farming is important contributors to their household income. On 5-point semantic scale the $83.68 \%$ of the farmer's rate $<3$ livestock with a statistical significance of $p=<.0001 .94 .67 \%$ of the farmers indicated poultry as an important contributor to household income $(\mathrm{p}=<.0001)$. Hundred percent $(100.0 \%)$ of the farmers indicated crop production (field crops) as a major contributor to household income ( $\mathrm{p}=<.0001$ ). And $90.33 \%$ of the farmers indicated horticulture or garden crops has an important household income contributor $(p=0.0001)$. Income Household diversification is a risk aversion strategy and livelihood strategy; the enterprises that are carried out during different seasons hence giving constant income for the household throughout the year [9].

Table 2. Farming enterprises carried out by the communal farmers and level of importance $(N=150)$.

\begin{tabular}{|c|c|c|c|c|c|c|c|c|c|c|c|c|c|}
\hline \multirow{3}{*}{ Source of income } & \multicolumn{10}{|c|}{ Ratings } & \multirow{2}{*}{\multicolumn{3}{|c|}{ Chi-Square Test }} \\
\hline & \multicolumn{2}{|l|}{1} & \multicolumn{2}{|l|}{2} & \multicolumn{2}{|l|}{3} & \multicolumn{2}{|l|}{4} & \multicolumn{2}{|l|}{5} & & & \\
\hline & $\mathbf{F}$ & $\%$ & $\mathbf{F}$ & $\%$ & $\mathbf{F}$ & $\%$ & $\mathbf{F}$ & $\%$ & $\mathbf{F}$ & $\%$ & $\mathbf{X}^{2}$ & df & $\mathbf{p}$ \\
\hline Livestock & 8 & 5.67 & 15 & 10.64 & 46 & 32.62 & 37 & 26.24 & 35 & 24.82 & 36.2695 & 4 & $<.0001$ \\
\hline Poultry & 0 & 0 & 7 & 4.67 & 19 & 12.67 & 76 & 50.67 & 48 & 32.00 & 76.4000 & 3 & $<.0001$ \\
\hline Crop production (field crops) & 0 & 0 & 0 & 0 & 19 & 12.67 & 100 & 66.67 & 31 & 20.67 & 76.4400 & 2 & $<.0001$ \\
\hline Horticulture (gardening) & 0 & 0 & 14 & 9.33 & 50 & 33.33 & 45 & 30.00 & 41 & 27.33 & 20.7200 & 3 & $<.0001$ \\
\hline
\end{tabular}

Table 3, below shows the field crops grown by the farmers and their contribution to the household finance. All the farmers indicated that maize contributes to their household income $(p=0.0105)$. Maize is not only for household consumption but also for selling; [9] communal farmers are the major producer of maize in Zimbabwe. Zimbabwe has been experiencing seasonal droughts for the past five years and any surplus maize fetch good prices especially on the market [10]. About Sixty-three percent of the farmers indicated that soybeans are a major contributor of household finance $(\mathrm{p}=<.000)$.

Soybeans processing to commonly product called "chunks" is big business for small agro-processing plants in Zimbabwe, so soybeans is in high demand and a good source of income for the farmers. Soybeans share the same value addition sequence as the groundnuts [11].
About $90.25 \%$ of the farmers indicated that groundnuts are a major contributor of household income ( $p=<.0001)$, processing of groundnuts to peanut butter is also big business Zimbabwe, small agro-process firms, and farmers themselves process groundnuts for peanut butter which fetch way better prices than selling groundnuts [11].

All the farmers indicated that tobacco is a major contributor of household finance $(p=0.1496)$. Tobacco is a major cash crop in Zimbabwe and since the collapse of commercial tobacco agricultural production, smallholder farmers which include communal farmers started also growing tobacco [11]. However, it is not tobacco alone which is grown other crops such as soybean $(p=<0.0001)$, and groundnuts $(\mathrm{p}=<0.0001)$ are also major household contributors for field crop (see Table 3 below). 
Table 3. Field crops grown and their contribution to household finance contribution (N=150).

\begin{tabular}{|c|c|c|c|c|c|c|c|c|c|c|c|c|c|}
\hline \multirow{3}{*}{$\begin{array}{l}\text { Source of } \\
\text { income }\end{array}$} & \multicolumn{10}{|c|}{ Ratings } & \multirow{2}{*}{\multicolumn{3}{|c|}{ Chi-Square Test }} \\
\hline & \multicolumn{2}{|l|}{1} & \multicolumn{2}{|l|}{2} & \multicolumn{2}{|l|}{3} & \multicolumn{2}{|l|}{4} & \multicolumn{2}{|l|}{5} & & & \\
\hline & $\mathbf{F}$ & $\%$ & $\mathbf{F}$ & $\%$ & $\mathbf{F}$ & $\%$ & $\mathbf{F}$ & $\%$ & $\mathbf{F}$ & $\%$ & $\mathrm{X}^{2}$ & df & $\mathbf{p}$ \\
\hline Maize & 0 & 0 & 0 & 0 & 36 & 24 & 66 & 44 & 48 & 32 & 9.1200 & 2 & 0.0105 \\
\hline Soybeans & 0 & 0 & 15 & 36.59 & 25 & 60.98 & 1 & 2.44 & 0 & 0 & 21.2683, & 2 & $<.0001$ \\
\hline Paprika & 0 & 0 & 9 & 45 & 7 & 35 & 4 & 20 & 0 & 0 & 1.9000 & 2 & 0.3867 \\
\hline Sorghum & 24 & 36.96 & 32 & 48.48 & 10 & 15.15 & 0 & 0 & 0 & 0 & 11.2727, & 2 & 0.0036 \\
\hline Tobacco & 0 & 0 & 0 & 0 & 8 & 20 & 18 & 45 & 14 & 35 & 3.8000 & 2 & 0.1496 \\
\hline Groundnuts & 0 & 0 & 8 & 9.76 & 30 & 36.59 & 34 & 41.46 & 10 & 12.20 & 26.2927 & 3 & $<.0001$ \\
\hline
\end{tabular}

Table 4, shows the reasons for the ratings on the importance of the field crops and their household income contributions with statistically significant of $\mathrm{p}=<.0001$. $38.5 \%$ of the farmers grow maize because it is easy to sell locally, and that maize is easy to sell on an open market, which generally fetches good prices. The recent droughts made maize to be a sought-after produce, because of scarcity.
Maize is also a staple crop, so it is always in demand. Farmers who indicated they grow tobacco because it fetches good prices on the market and has more established markets. Sorghum is generally grown for household consumption only; this is because sorghum is used for traditional beer and also for household consumption [12].

Table 4. Reasons for the ratings on importance of field crops grown and their contribution to household income (N=150).

\begin{tabular}{lll}
\hline & Frequency & \% \\
\hline Maize is easy to sell locally & 62 & 38.5 \\
Tobacco prices are good & 44 & 27.3 \\
Groundnut fetches good prices when processed to peanut butter & 23 & 14 \\
Poor prices for maize as the prices are regulated by the government & 14.3 \\
Soybeans has poor prices & 8.7 \\
Sorghum is mostly for household consumption & 7.5 \\
Total & 3.7 & 12 \\
\hline
\end{tabular}

Table 5, below shows the horticultural crops also referred to as garden crops, contribution to household income. The local dietary of most of the people is made up of tomatoes, spinach and cabbages, these vegetables are the highest earners for the communal farmers. About $88.01 \%$ rated that cabbages are the highest contributors to their household income $(\mathrm{p}=0.0006)$. Besides cabbages being a major contributor to household income, cabbage is also a major relish. Besides cabbages the other biggest contributor to household income are tomatoes, $85.34 \%$ rated $>3$ on a 5 point semantic scale, that tomatoes are a major contributor to their household income $(\mathrm{p}=<.0001)$.

Table 5. Horticulture crops grown and their contribution to household finance contribution $(N=150)$.

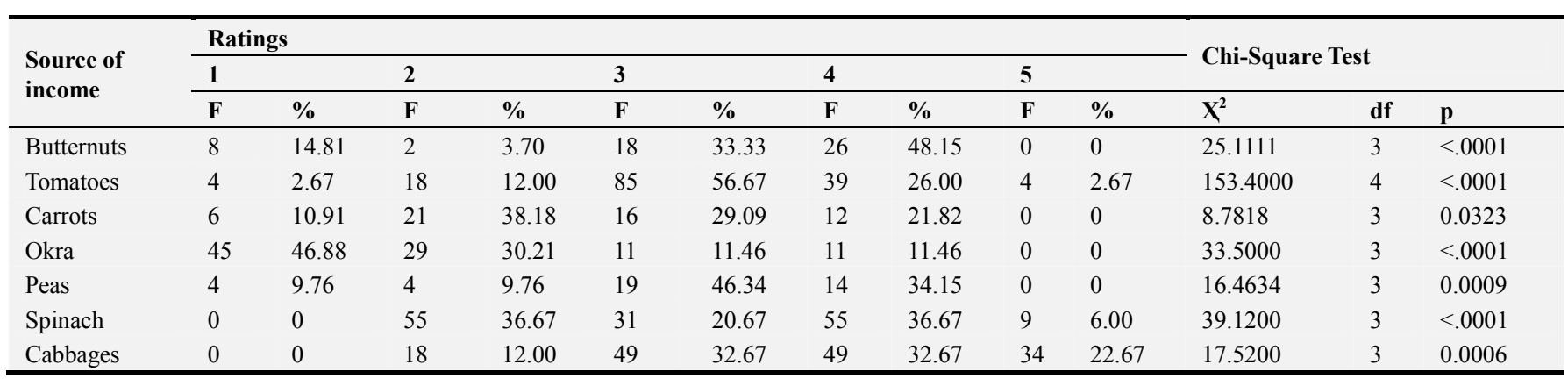

Table 6, below shows the reasons for the ratings on the importance of the garden produce and their contribution to household income. $37.74 \%$ of the farmers gave the reasons that they grow butters and tomatoes, okra, spinach and cabbages because they can easily be sold locally with no transport costs involved. $54.09 \%$ of the farmers said that they grow butternuts, cabbages and tomatoes because they fetch good prices at the open markets in Harare (Mbare Musika). Mbare Musika is the biggest open trading market for vegetables and fruits in Zimbabwe. It is a distribution centre for agricultural produce in Zimbabwe with millions of dollars' worth of trade happening daily [13]. The reasons given by the communal farmers a statistically significant ( $p$ $=<.0001$ ). 
Table 6. Reasons for the ratings on importance of horticulture crops grown and their contribution to household income (N=150).

\begin{tabular}{lll}
\hline & Freq & \% \\
\hline Butters and tomatoes, okra, spinach and cabbages are sold locally no transport cost is involved & 60 & 37.74 \\
Butternuts, cabbages and tomatoes fetch good prices at the open markets in Harare (Mbare Musika) & 86 & 54.09 \\
I grow vegetables for household consumption & 13 & 8.18 \\
Total & 169 & 100.0 \\
\hline
\end{tabular}

Table 7, below shows the livestock/poultry enterprises done by the farmers, and their household contribution. $83.33 \%$ of the farmers rated that chicken production is the most important household income contributor, with statistical significance of $\mathrm{p}=<.0001$. According to the farmer's chickens are easy to keep and generally are kept on free range basis.
They are also a steady source of protein for the household. Chicken rearing is then followed by goats rearing in regards to household income contribution with $67.48 \%$ of the farmers rating $>3$ on 5 -point semantic scale, with statistical significance, $\mathrm{p}=0.1205$.

Table 7. Livestock/poultry as a farming enterprise and household financial contribution $(N=150)$.

\begin{tabular}{|c|c|c|c|c|c|c|c|c|c|c|c|}
\hline \multirow{3}{*}{$\begin{array}{l}\text { Source of } \\
\text { income }\end{array}$} & \multicolumn{8}{|c|}{ Ratings } & \multirow{2}{*}{\multicolumn{3}{|c|}{ Chi-Square Test }} \\
\hline & 1 & & 2 & & 3 & & 4 & & & & \\
\hline & $\mathbf{F}$ & $\%$ & $\mathbf{F}$ & $\%$ & $\mathbf{F}$ & $\%$ & $\mathbf{F}$ & $\%$ & $X^{2}$ & df & $\mathbf{p}$ \\
\hline Cattle & 64 & 42.67 & 40 & 26.67 & 23 & 15.33 & 23 & 15.33 & 30.1067 & 3 & $<.0001$ \\
\hline Goats & 0 & 0 & 14 & 32.56 & 20 & 46.56 & 4 & 20.93 & 4.2326 & 2 & 0.1205 \\
\hline Sheep & 3 & 27.27 & 8 & 72.73 & 0 & 0 & 0 & 0 & 2.2727 & 1 & 0.1317 \\
\hline Chicken & 0 & 0 & 25 & 16.67 & 72 & 48.00 & 53 & 35.33 & 22.3600 & 2 & $<.0001$ \\
\hline
\end{tabular}

Table 8, below shows the reasons for the rating on importance of livestock/poultry and their contribution to household income. $20.25 \%$ of the communal farmers engaged in poultry because it is a source of quick and steady income. Poultry especially chickens are easy to grow and have readily market [13]. Communal farmers keep chickens on free range so there are to reduce pressure on feeding the chicken. Chickens also eat the food household leftovers and also are given grain at sporadic times. The reasons for the low rating for the livestock include; too much transport cost involved, and poor markets for livestock.

Table 8. Reasons for the ratings on importance of livestock/poultry as a farming enterprise and household financial contribution (N=150).

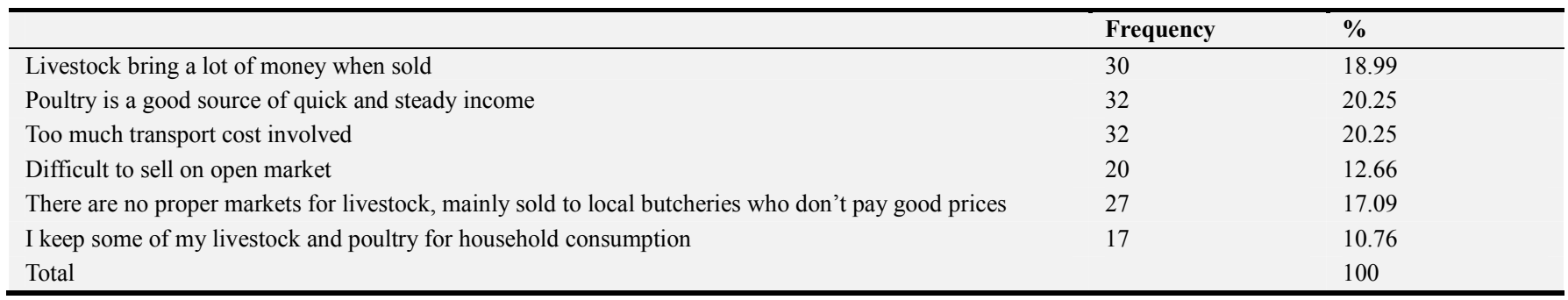

\section{Conclusion}

Agricultural product types and household income contribution is an important aspect of rural economics. Rural economic development and growth acknowledges that agriculture is one of the primary pillars of rural development in Zimbabwe [14]. According to the results, remittances and gifts $(92.66 \%)$ are the major contributors of household income for most communal farmers. This is because of the current bad economic situation and frequent droughts. Despite remittances and gifts being the major household income, farmers still perceive farming has very important contributor to their daily sustenance. The study proves that field crops and maize in particular is a strategic crop in Zimbabwe. Maize is not only for household consumption but also for selling. According to Communal farmers are the major producer of maize in Zimbabwe. Relevant interventions from the government need to be in place to increase maize production in Zimbabwe and communal farmers are a strategic point [14].

Tobacco is the most important cash crop for the farmers because of good prices and well-established markets. Tobacco auction floors in Zimbabwe are the most secure markets for the farmers, and tobacco contract farming is the most preferred by the farmers [9]. Garden crops and poultry are important for household consumption and selling on the open market. Farmers indicated that open markets are important but because of unscrupulous traders and lack of monitoring and poor regulations, farmers are prone to being cheated and price manipulations. The government and private sector can contribute in formalizing and improving growing of garden crops. Strategic crops/vegetables include tomatoes and cabbages, interventions such has as improving access to finance, processing of these vegetables would an invaluable contribution to the rural economy. The government should 
improve and invest in non-farm economy which contributes to communal farmer standard of leaving such has roads, electricity, and related infrastructure. This will inherently improve the farm economy and the livelihood status of the communal farmers.

\section{References}

[1] Glover, D., \& Kusterer, K. (2016). Small farmers, big business: contract farming and rural development. Springer.

[2] Meyers, G. P. (2015). Decolonizing a Food System: Freedom Farmers' Market as a Place for Resistance and Analysis. Journal of Agriculture, Food Systems, and Community Development, 5(4), 149-152.

[3] Sojl, Z., Chikwanda, D., Jaja, I. F., Mushonga, B., \& Muchenje, V. (2015). Relevance of the formal red meat classification system to the South African informal livestock sector. South African Journal of Animal Science, 45(3), 263277.

[4] Naziri, D., Rich, K. M., \& Bennett, B. (2015). Would a commodity-based trade approach improve market access for Africa? A case study of the potential of beef exports from communal areas of Namibia. Development Policy Review, 33(2), 195-219.

[5] Mmbengwa, V., Nyhodo, B., Myeki, L., Ngethu, X., \& van Schalkwyk, H. (2015). Communal livestock farming in South Africa: Does this farming system create jobs for poverty stricken rural areas?. Sylwan, 159(10), 176-192.

[6] Altieri, M.A., 2018. Agroecology: the science of sustainable agriculture. CRC Press.
[7] Muchesa, E., 2013. Sustainable extension support to land reform beneficiaries in Zimbabwe (Mashonaland West) (Master dissertation, Department of Agriculture Economics, Extension \& Rural Development, University of Pretoria).

[8] Samphantharak, K., \& Townsend, R. M. (2018). Risk and return in village economies. American Economic Journal: Microeconomics, 10(1), 1-40.

[9] Alobo Loison, S. (2015). Rural livelihood diversification in sub-Saharan Africa: a literature review. The Journal of Development Studies, 51(9), 1125-1138.

[10] Pritchard, R., Ryan, C. M., Grundy, I., \& van der Horst, D. (2018). Human Appropriation of Net Primary Productivity and Rural Livelihoods: Findings From Six Villages in Zimbabwe. Ecological Economics, 146, 115-124.

[11] Mashizha, T. M., Monga, M., \& Dzvimbo, M. A. (2017). Improving Livelihoods of Resettled Farmers Through Development of a Knowledge Base on Climate Change in Mhondoro-Ngezi District, Zimbabwe. International Journal of Sustainable Development Research, 3(2), 18.

[12] Mavhura, E. (2017). Applying a systems-thinking approach to community resilience analysis using rural livelihoods: The case of Muzarabani district, Zimbabwe. International Journal of Disaster Risk Reduction, 25, 248-258.

[13] Scoones, I., Mavedzenge, B., Murimbarimba, F \& Sukume, (2017). Tobacco, contract farming, and agrarian change in Zimbabwe. Journal of Agrarian Change. Volume18, Issue1, January 2018, Pages 22-42. https://doi.org/10.1111/joac.12210

[14] Commercial Farmers Union of Zimbabwe Congress., 2016. Commercial Farmers' Union of Zimbabwe Annual Congress (2016). "Building Agricultural Competitiveness in Zimbabwe" http://www.cfuzim.org/ cfuzimb/images/brochure2016.pdf 